\title{
ARE SAFETY DATA SHEETS FOR CLEANING PRODUCTS USED IN NORWAY A FACTOR CONTRIBUTING TO THE RISK OF WORKERS EXPOSURE TO CHEMICALS?
}

\author{
ABDULQADIR M. SULEIMAN ${ }^{1}$ and KRISTIN V. H. SVENDSEN ${ }^{2}$ \\ ${ }^{1}$ Labour Inspection Authority, Oslo, Norway \\ Market Surveillance of Chemicals \\ ${ }^{2}$ Norwegian University of Science and Technology, Trondheim, Norway \\ Institute of Industrial Economics and Technology Management
}

\begin{abstract}
Objectives: Cleaning products are considered less hazardous than those used in other sectors. Suppliers and distributors are less conscientious when it comes to informing users on health risks. The aim of the study was to elaborate on the usefulness and clarity of information in the safety data sheets (SDS) for cleaning products, and considering if the use of these SDSs can be seen as a risk factor towards occupational exposure to hazardous chemicals in the sector. Material and Methods: Safety data sheets were selected based on the risk level of the product assigned in an industrial sector scheme. 320 SDSs for cleaning products were reviewed. Constituent components found in the products over a given threshold were listed and available information thereof used to assess the perceived non-hazard consideration of the chemicals. Results: The contents of the SDSs was generic and mostly incomplete. Safety measures and health information lacked sufficient specificity despite varying compositions and concentrations of components. There is generally incompatibility between mentioned sections on the suggested non-hazardous nature of the products and health effects. Not all substances used in these products have harmonized classifications, which makes them open to various classification of the products and the suggested safety measures. This results in different companies classifying similar products differently. Risk management measures and suggested personal protective equipment (PPEs) are given haphazardly. Physical properties relevant to risk assessment are not included. Conclusions: The safety data sheets are ambiguous, and they lack relevant and important information. Inadequate information and risk assessment concerning the products can lead to workers being exposed to hazardous chemicals. Underestimation of the hazard contribution of the components of the products and the insufficient, non-objective mention of appropriate control and protective measures are the major contributing elements. There is a need to test the products in order to establish health effects and product specific safety measures.
\end{abstract}

Key words:

Cleaning workers, Safety data sheets, Cleaning products, Health information, Constituent components, Safety measures

\section{INTRODUCTION}

Cleaning sector is one of the major end-users of chemical products. Information from the Norwegian Product Register (central register for chemicals in Norway) shows that, in 2012, 271000 tons of cleaning chemicals were registered. This amount includes only those chemicals classified in 1 or more hazard classes, and does not include biocides. Approximately, 42800 tons of the total

Received: March 6, 2014. Accepted: June 19, 2014.

Corresponding author: A.M. Suleiman, Labour Inspection Authority, Market Surveillance of Chemicals, Post Box 8174 Dep, 0034 Oslo, Norway (e-mail: ams@arbeidstilsynet.no). 
amount $(16 \%)$ were classified irritants only, with a little less than 700 tons of these having also sensitizing effects. The rest were classified in more than 1 hazard class. A common perception, however, amongst employers and employers' organization in the cleaning service sector is that cleaning products are less hazardous than chemicals used in other sectors. Safety data sheets (SDSs) and labels are for many workers, the only available source of information on the products they use.

Cleaning enterprises readily make SDSs available to their workers as this is a requirement of the law [1]. However, despite the seemingly widespread use of SDSs, there are serious problems with using the SDS as a tool for communication. It is reported that in 50-60\% of cases, important health information is missing in a standard SDS [2]. It is also generally known that, information provided in the SDS is, largely, generic and insufficient for the use in establishing safety paradigms at various workplaces [3]. Keegel et al. [4] postulated that SDSs are inadequate in providing information on the safe use of chemicals, and for use as a diagnostic tool for workers with suspected occupational diseases. This is because more often than not, essential information is omitted and efforts to obtain such information from manufacturers do not normally bear any positive results. Moreover, deficiencies can put workers at a risk of developing chronic occupational diseases [5]. Cleaning workers are among the occupational groups with the highest incidence of contact dermatitis [6,7], and they have an increased risk of asthma and rhinitis [8]. Increasingly, fingers are pointed towards cleaning products as the reason for up to $12 \%$ of the reported asthma cases in several countries across Europe [9].

The aim of this study was to qualitatively assess available information on cleaning chemicals in the form of SDS in order to establish its usefulness and clarity, i.e., utility and uniformity of purpose. It is essential that cleaning workers and others who use cleaning products have information that is correct and that enables them to make proper judgment of the hazardous risks involved. In so doing, the study would hopefully give premises for improving the quality of information given in the SDSs for cleaning products and other chemical products.

\section{MATERIAL AND METHODS}

The starting point was to collect SDSs for cleaning products. Products names and names of their respective suppliers were obtained from a list of registered products under a scheme run by the National Federation of Service Industry (NHO Service), an affiliate of Confederation of Norwegian Enterprise. The list contained a little over 650 products from altogether 34 suppliers. The scheme categorized the listed products into different risk classes based on hazard classification and criteria for categorization prepared by the National Institute of Technology (Teknologisk Institutt - TIN), an interdisciplinary competence firm on, among other things, safety. Table 1 shows the categories of the listed products, the risk levels along with areas of use of the products as is given in the SDS.

Information from the labels, SDS, and product component declaration, information from the Norwegian Product Register, the Poison Centre, user manuals and caution list maintained by the Norwegian authorities were used to set the categories and their respective risk levels. The important items in the determination of the risk classification of the products also included: $\mathrm{pH}$, presence of perfume and other additives, presence and type of solvent used in the mixture and whether the mixture contained any substances with special characteristics. Other relevant factors included information on whether the mixture contained a substance with complex-making properties and whether any of the substances in the mixture has any impact on the environment.

Although the scheme has been dormant since 2007, the list was still very valuable as a starting point for collection of the SDSs. SDSs for the products were searched from various 
Table 1. NHO-Service risk classes with corresponding classifications and areas of use of the cleaning products according to the safety data sheets (SDS)

\begin{tabular}{|c|c|c|c|c|}
\hline $\begin{array}{l}\text { NHO-service } \\
\quad \text { class }\end{array}$ & $\begin{array}{l}\text { Classification } \\
\text { in SDS according } \\
\text { to DPD [10] }\end{array}$ & $\begin{array}{l}\text { Risk level } \\
\text { assigned }\end{array}$ & $\begin{array}{c}\text { Area of use } \\
\text { (according to SDS) }\end{array}$ & $\begin{array}{c}\text { Criteria } \\
\text { for the NHO-classification }\end{array}$ \\
\hline 1 & not classified & minimal & $\begin{array}{l}\text { polish, floor cleaning, carpet cleaning, } \\
\text { floor wax }\end{array}$ & $\begin{array}{l}\mathrm{pH} \text { range: } 6-9 \text {, no perfumes added, } \\
\text { do not form aerosols }\end{array}$ \\
\hline 2 & $\begin{array}{l}\text { not classified, } \\
\text { irritants }\end{array}$ & low & $\begin{array}{l}\text { polish, floor wax, sealers, general } \\
\text { cleaning, strippers, detergents, } \\
\text { impregnation, glass and windows } \\
\text { cleaning, metal polish, fabric } \\
\text { softeners }\end{array}$ & $\begin{array}{l}\text { pH range: 5-10, may contain perfume } \\
\text { and coloring, may contain up to } 10 \% \\
\text { ethanol or 2-propanol; can be made } \\
\text { into aerosols; flammable substances; } \\
\text { hygienic air requirements: }<100 \mathrm{~m}^{3} / 1\end{array}$ \\
\hline 3 & irritants & medium & $\begin{array}{l}\text { disinfectants, general cleaning, polish } \\
\text { removers, toilet cleaning, kitchen } \\
\text { cleaning, impregnation, metal polish, } \\
\text { bleach, fabric cleaning }\end{array}$ & $\begin{array}{l}\text { pH range: } 2-5 \text { (acidic) or } 10-11.5 \\
\text { (alkali), may contain perfumes and } \\
\text { coloring, other organic solvents } \\
<10 \% \text {, may contain phosphonic } \\
\text { acid derivatives; make aerosols; } \\
\text { flammable substance; hygienic air } \\
\text { requirements: } 100-400 \mathrm{~m}^{3} / 1\end{array}$ \\
\hline 4 & $\begin{array}{l}\text { corrosive, harmful } \\
\text { allergy-causing }\end{array}$ & high & not included in the study & not included in the study \\
\hline 5 & toxic, CMR & very high & not included in the study & not included in the study \\
\hline IG & not approved & & not included in the study & not included in the study \\
\hline
\end{tabular}

NHO - National Federation of Service Industry; DPD - Dangerous Product Directive [10]; CMR - carcinogen, mutagen, reproduction toxicity; IG - products not categorized in one of the categories due to lack of sufficient information.

commercial providers of online SDS and substances records services as well as from the webpages of the suppliers. Classification of the products was not ascertained and was assumed in accordance with existing classification criteria.

\section{Study design}

The general quality of the SDSs with regard to their usability and uniformity of purpose of the information given was examined in detail. Only products from the risk classes 1-3 were included in the study.

Sections of importance in the SDS included:

- section 1 - the area of use,

- section 2 - classification and hazards of the chemicals,

- section 3-constituent elements of the mixture,

- section 4 - first aid measures,

- section 8 - exposure control,
- section 9 - physical properties,

- section 11 - toxicological information.

Physical properties in section 9 are relevant in workplace risk assessment. Information on health hazards, exposure control, personal protective equipment and toxicological information was assessed and compared to check for consistency of hazard expression. This was performed in order to illustrate how well the SDSs make good source of information and whether they give foundation for safe use, and for reduction of the risk of exposure of users of the products.

As for the components present in the products, only those with concentration $\geq 1 \mathrm{w} / \mathrm{w} \%$ were considered, as this is the threshold concentration for irritation classification [10]. Perfumes were included despite their below threshold concentration due to their sensitizing potential. 
Other SDSs for products not on the list were not included in the study as similar assessment and categorization is not available for the non-listed products. To classify the products according to the scheme was beyond the scope of this study. All SDSs were in Norwegian, in compliance with existing regulation.

\section{RESULTS}

From 22 suppliers, SDSs for 320 of the 650 listed products fulfilled the selection criteria. As for the remaining 330 products, 111 were for those in risk classes 4, 5 and those with not sufficient information, labeled IG. Another 86 were from enterprises which have since closed down; and SDSs for 133 products could not be found, most likely due to the fact that the products were no longer available on the market.

All the SDSs in the study had identical product name, classification, product number where applicable and supplier as was given in the NHO-list. Cleaning products are mostly mixtures, and the constituent components may have changed since the time the list was made, which might have changed the risk level. Despite this, the assigned risk classes for the products were kept for the purpose of this study.

Of the 320 SDS assessed, 70\% ( $\mathrm{N}=225)$ were written in ECO-publisher format (an SDS-format offered by a consultant firm). SDSs from large enterprises were not distinguishable in content from those from smaller enterprises. The revision dates on the SDSs showed that generally, the SDSs were recently revised, some as recently as in mid-2013, and were prepared and written according to the legislative requirements. SDSs for 92 (29\%) products were prepared in the format of the EU-regulation 453/2010 [11], which amended annex II of the 1907/2006 regulation on Registration, Evaluation, Authorization of Chemicals $(\mathrm{REACH})$. Few SDS, $8 \%(\mathrm{~N}=26)$ predated REACH. These were not analyzed further because they are no longer valid.

\section{Area of use}

Based on the SDSs information, the products were divided into 6 groups as shown in Table 2. Most products, $61 \%$ $(\mathrm{N}=194)$, were under risk class 2 . In describing the areas of use, 35 SDSs (ca. 11\%) were most elaborate and were among those written in regulation 453/2010 format. They also included sector of use (SU), product category (PC) and environmental release category (ERC) references, as are defined in the REACH guidance document on use descriptor system [12]. Areas of use that are advised against were only partly mentioned.

Where regulation 453/2010 was applied, variations on specificity and clarity of the information were still apparent and substantial. Only the area of use, such as floor polish, disinfectant, glass cleaning, is given the least description. In 60 of the 224 SDSs $(27 \%)$ for

Table 2. Safety data sheets of different products and their risk classes

\begin{tabular}{lccccccr}
\hline & \multicolumn{7}{c}{ Type of cleaning chemical } \\
\cline { 2 - 7 } $\begin{array}{c}\text { NHO-service } \\
\text { class }\end{array}$ & $\begin{array}{c}\text { polish/waxes, } \\
\text { floor agents }\end{array}$ & $\begin{array}{c}\text { general } \\
\text { cleaning, } \\
\text { scrubs, } \\
\text { disinfectants }\end{array}$ & impregnation & $\begin{array}{c}\text { glass, } \\
\text { windows }\end{array}$ & metal polish fabric softeners & total \\
\hline 1 (minimal risk) & 19 & 12 & 2 & 1 & 0 & 0 & 34 \\
2 (low risk) & 45 & 133 & 6 & 7 & 2 & 1 & 194 \\
3 (medium risk) & 0 & 79 & 1 & 2 & 1 & 9 & 92 \\
Total & 64 & 224 & 9 & 10 & 3 & 10 & 320 \\
\hline
\end{tabular}


general cleaning products only "detergent" is given as the area of use.

A reasonable assumption would be that the safety information given was determined according to the areas of use and the constituent components of the products, and to considerable extent the risk level the products are classified in. However, despite the different risk levels and composition of the products, the SDSs lack specificity. Similar information is given for the products with different risk levels and containing different components, e.g., a risk class 1 - polish of most polymers make-up and class 2 fabric softener containing mostly citric acid (Citric acid b.p. $350^{\circ} \mathrm{C}$ ) and an organic sulphate, are all given boiling point at $100^{\circ} \mathrm{C}$ and are mild skin and airway irritants. PVC gloves are suggested in all the cases. Such inconsistencies are found across different products groups.

\section{Consistency on health hazard information}

Due to non-hazardous or irritant classification of the products, information provided in the SDSs is minimal. This is misleading as non-hazardous classification does not necessarily mean non-hazardous effects [13]. It is necessary that hazard descriptions relate to and are consistent with toxicological information available. In the examined SDSs there are clear inconsistencies between these, and also in the case of exposure control measures.

The standard risk/hazard $(\mathrm{R} / \mathrm{H})$ and safety/precautionary $(\mathrm{S} / \mathrm{P})$ phrases give guidance on how to handle the products safely. This information along with other statements used in the SDS, are labeled "Cautions," while statements indicating safeness from suppliers' own assessment, are labeled "Assurances." Cautions and Assurances provided in the SDSs are listed in Table 3 as evidence on the quality of the information, and as elucidation on how sections within the same SDS contrast each other, impacting negatively on their usefulness and clarity. Phrases such as "proper/normal use," "good hygienic practices," components with "reporting requirements" need clarifications and explanations in order to be properly understood. Precise comprehension of those and similar statements is relevant to risk assessment.

It is required that in the cases where exposure scenarios as part of chemical safety assessment are available, reference to information therein is to be made in the SDS [14]. No such references are made in any of the SDSs assessed. Exposure scenarios are expected to be more specific on safety measures for individual types of use.

Another finding associated with inconsistency is that SDS with no statement of solvent content, as a control measure, had given use of gas mask with filter type A, indicating a risk of considerable solvent exposure.

\section{Components and health hazard}

Components listed in section 3 of the SDS are directly correlated with classification of the product. In the case of 22 SDSs (ca. 7\%), no components were listed. Five of these listed had at least one component with an assigned occupational exposure limit (OEL) value under section 8. No information on any associated hazards is made in section 2. This lack of information makes it extremely arduous to assess whether the safety measures given are adequate.

The components identified were grouped according to their commonality. This gave the 8 groups presented in Table 4. All substances were identified with their CAS numbers except the non-identified surfactants and surface-active substances. The most predominant substance across all the product types is 2-(2-ethoxyethoxy)ethanol, CAS No. 111-90-0. This substance is a component in 40 of the $64(62.5 \%)$ polishes/waxes in both, class 1 and 2 . This substance has a non-harmonized classification, but is considered Eye Irrit. 2 H319, Acute Tox. 4 H302, Acute Tox. $3 \mathrm{H} 331$ by industrial self-classification [15]. Other product types also contained this substance and/or other types of glycol ethers. Glycol ethers have been increasingly used as components in aqueous cleaning products [16]. 
Table 3. Contrasting risk and safety statements used in the safety data sheets*

\begin{tabular}{|c|c|}
\hline $\begin{array}{l}\text { "Assurance" of no health hazards } \\
\text { resulting from the use of the products }\end{array}$ & $\begin{array}{l}\text { "Cautions" on health hazards } \\
\text { of the products }\end{array}$ \\
\hline $\begin{array}{l}\text { No hazardous effects expected or known under normal/ } \\
\text { proper use } \\
\text { No health risk when good hygienic practices are followed }\end{array}$ & $\begin{array}{l}\text { Use gloves under repeated use } \\
\text { Prolonged use may cause irritation of the skin and airways } \\
\text { Causes drying of the skin and irritation of the airways }\end{array}$ \\
\hline Contains no component with reporting requirement & $\begin{array}{l}\text { Contains perfumes/substances that are known to cause allergies } \\
\text { in those sensitized } \\
\text { Contains anionic/cationic surfactants }\end{array}$ \\
\hline No data on specific health effect available & $\begin{array}{l}\text { Ingestion can give diarrhea, irritation of the alimentary system, } \\
\text { and vomiting } \\
\text { Ingestion causes stomach pain and discomfort } \\
\text { Do not induce vomiting if swallowed due to aspiration hazard }\end{array}$ \\
\hline Not expected to cause allergy & $\begin{array}{l}\text { Sensitized individuals should avoid contact with the product } \\
\text { Can cause allergies to sensitized individuals } \\
\text { Contain small amount of substance known to cause allergic } \\
\text { reaction }\end{array}$ \\
\hline $\begin{array}{l}\text { Respirators not needed } \\
\text { The product does not contain volatile components }\end{array}$ & $\begin{array}{l}\text { Inhalation of vapors causes dizziness, headache and nausea } \\
\text { In poorly ventilated places, use mask with filter type A } \\
\text { Workers exposed to concentrations above limit values should use } \\
\text { suitable and approved gas masks }\end{array}$ \\
\hline Eye protection not necessary & $\begin{array}{l}\text { Can cause serious eye damage } \\
\text { Where there is danger for direct contact and splash, protective } \\
\text { goggles must be used }\end{array}$ \\
\hline $\begin{array}{l}\text { No known chronic effects } \\
\text { Do not contain substance with carcinogenic, mutagenic } \\
\text { and reproductive toxic properties }\end{array}$ & Can give adverse long-term effects \\
\hline $\begin{array}{l}\text { The product is not classified as hazardous, no special safety } \\
\text { measures are necessary }\end{array}$ & $\begin{array}{l}\text { Information should not be taken as a guarantee or as quality } \\
\text { specification } \\
\text { Information is given according to what is provided us by } \\
\text { the supplier and according to existing regulations } \\
\text { It is the responsibility of the user to make sure that the } \\
\text { information is read and understood } \\
\text { In that workplace conditions are beyond our scope, users have } \\
\text { own responsibility to implement correct precautions }\end{array}$ \\
\hline
\end{tabular}

* The statements were translated from Norwegian to English by the author.

These cleaning products, being complex mixtures of active agents, make determination of risk of health hazard arduous [16].

General cleaning products and disinfectants contain mostly esters, quaternary ammonium compounds, acids, bases and their salts. Sixty-five products (20\%) contained one or more types of perfume and/or other components known to cause skin allergies. A total of 57 substances $(63 \%)$ lacked harmonized classification. Among these 57 substances with non- harmonized classification, 29 (32\%) are suggested to be CMR (carcinogen, mutagen, reproduction toxicity), STOT SE or STOT RE (specific target organ toxicity single/repeated exposure) [15]. Taking organic and inorganic acids/bases and their salts as an example, the 
Table 4. Substances identified in the safety data sheets along with information on toxicity

\begin{tabular}{|c|c|c|c|c|}
\hline Substance group & Substance & $\begin{array}{l}\text { Non- } \\
\text { harmonized } \\
\text { classification }\end{array}$ & $\begin{array}{c}\text { Non- } \\
\text { harmonized } \\
\text { classification } \\
\text { (suggested to } \\
\text { be CMR/STOT } \\
\text { SE/RE) }\end{array}$ & $\begin{array}{l}\text { General information } \\
\text { on toxicity }\end{array}$ \\
\hline $\begin{array}{l}\text { Glycol ethers (alkoxyalcohols } \\
\text { and their derivatives) (n) }\end{array}$ & 8 & 5 & 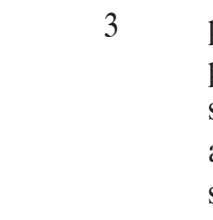 & $\begin{array}{l}\text { potential for absorption through the skin; } \\
\text { prolonged and repeated use may lead to } \\
\text { severe skin irritation; target organ toxicity } \\
\text { associated with specific metabolites of these } \\
\text { substances [17] }\end{array}$ \\
\hline $\begin{array}{l}\text { Alcohols (substituted } \\
\text { and non-substituted) (n) }\end{array}$ & 12 & 5 & 3 & same as for ethers above \\
\hline $\begin{array}{l}\text { Esters (ethoxylated esters } \\
\text { and their derivatives) (n) }\end{array}$ & 11 & 10 & 2 & $\begin{array}{l}\text { considered to have similar toxicological effects } \\
\text { as their parent ether [17] }\end{array}$ \\
\hline $\begin{array}{l}\text { Organic ammonium quaternary } \\
\text { compounds }(\mathrm{n})\end{array}$ & 11 & 8 & 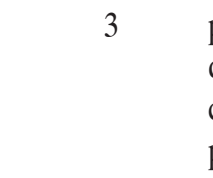 & $\begin{array}{l}\text { possible uptake through all uptake pathways; } \\
\text { dilute solutions can cause skin irritation; when } \\
\text { concentrated can cause severe burns; can } \\
\text { produce systemic toxicity [18] }\end{array}$ \\
\hline $\begin{array}{l}\text { Organic and inorganic acids/bases } \\
\text { and their salts (n) }\end{array}$ & 32 & 19 & 15 & $\begin{array}{l}\text { organic salts (mostly sulphates) can, under } \\
\text { prolonged use, penetrate the skin [19] }\end{array}$ \\
\hline $\begin{array}{l}\text { Perfumes and other known allergy } \\
\text { causing substances (n) }\end{array}$ & 10 & 5 & 1 & $\begin{array}{l}\text { most perfumes are known to be skin sensitizers; } \\
\text { labeled R43/Skin Sens. } 1, \text { H317 }\end{array}$ \\
\hline $\begin{array}{l}\text { Other hydrocarbons (butane, mineral } \\
\text { oil, naphtha, paraffin) (n) }\end{array}$ & 5 & 3 & $2^{c}$ & $\begin{array}{l}\text { known for drying up of skin and aspiration } \\
\text { hazard; petroleum distillates may be classified } \\
\text { as carcinogens due to presence of other } \\
\text { substances, e.g., PAH, benzene, DMSO }\end{array}$ \\
\hline $\begin{array}{l}\text { Carbonyl compounds and others; } \\
\text { non-identified anionic/cationic } \\
\text { surfactants and surface active } \\
\text { substances (n) }\end{array}$ & 2 & 2 & - & \\
\hline Total [n (\%)] & $91(100)$ & $57(63)$ & $29(32)$ & \\
\hline
\end{tabular}

CMR - carcinogen, mutagen, reproduction toxicity; STOT SE/RE - specific target organ toxicity single/repeated exposure.

${ }^{c}$ Due to presence of benzene or butadiene impurities in the hydrocarbon.

suggested classification for 15 of the 19 substances with a non- harmonized classification is CMR, STOT SE or STOT RE. Products containing these 29 substances with suggested CMR, STOT SE or STOT RE properties were classified as irritant or non-hazardous indicating that the non-harmonized classification assigned to the substances was not taken into consideration.
It is worthy to note that in the case of all the SDSs, the total amount of given components did not add up to $100 \%$. In $8 \%(\mathrm{~N}=29)$ of all the SDSs, the upper limits of the amount of components added up to about 30-50\%. Table 5 shows the sample mode concentration intervals (w/w \%) for various substance groups in different risk classes. Table 6 shows the substances given in higher 
Table 5. Sample modes of concentration intervals for substance groups in the 3 risk level

\begin{tabular}{lccc}
\hline \multirow{2}{*}{\multicolumn{1}{c}{ Substance group }} & \multicolumn{3}{c}{$\begin{array}{c}\text { Sample mode concentration interval } \\
\text { for each risk category } \\
\text { (w/w \%) }\end{array}$} \\
\cline { 2 - 4 } Glycol ethers (alkoxyalcohols and their derivatives) & class 1 & class 2 & class 3 \\
Alcohols (substituted and non-substituted) & $1-5$ & $1-5$ & $5-10$ \\
Esters (ethoxylated esters and their derivatives) & $5-10^{\mathrm{d}}$ & $1-5$ & $5-15$ \\
Organic ammonium quaternary compounds & $1-5$ & $1-5$ & $5-15$ \\
Organic and inorganic acids/bases and their salts & $5-10^{\mathrm{e}}$ & $1-5$ & $5-10$ \\
Perfumes and other known allergy causing substances & - & $1-5$ & $5-15$ \\
Other hydrocarbons (butane, mineral oil, naphtha, paraffin) & $<1$ & $<1$ & $<1$ \\
Carbonyl compounds & - & $5-10$ & $15-30$ \\
\hline
\end{tabular}

w/w - weight/weight.

${ }^{\mathrm{d}}$ Four out of 7 products with alcohols in this concentration interval.

${ }^{\mathrm{e}}$ Three out of 5 products with quaternary organic ammonium compounds in this concentration interval.

amounts. Four substances are given in intervals where the higher limit exceeds $50 \%$, and these 4 substances are found in 11 of the 29 products.

Polishes/waxes contained co-polymers in high concentration intervals (30-60\%). These polymers are not classified as hazardous and therefore, are not taken into account. Even with the presence of the substances in the intervals given in Table 6, the concentration still remained lower than $100 \%$. Other components making up the mixtures are not mentioned in the SDSs and thus, are not known to both the risk assessors and the users. Therefore, it is not possible to deduce from the information contained in the SDSs what other types of substances or solvents are used, apart from the cases where water is given as the solvent.

\section{First aid measures}

First aid measures contained in the SDSs of the different products are a good match with different risk levels. "Symptomatic treatment" is given as information for medical personnel in 65 SDSs. However, this information is not helpful as it does not advise on specific symptoms one should look for. Regulation 453/2010 requires that symptoms of exposure are listed [11]. None of the 92 SDSs written according to the regulation 453/2010 had the symptoms of eventual exposure indicated in spite of the fact that it is required according to the regulation. The information given is an attempt to present an inclusive system to cover all the potential consequences of the product, rather than as a useful tool for a potential user [20]. Probably the information provided may be sufficient for some products, but not for all of them.

\section{Personal protective equipment (PPE)}

Information on PPEs should be based on empirical tests performed using accepted methods [21]. With regard to gloves, in all the assessed SDSs, the suggested types of material are: non-specific rubber or plastic gloves. Statements used in the SDSs indicate that either the products were not tested for suitable glove material type or that the material type was suggested based on the components of the product and by the use of known gloves guides. It should be taken into consideration that a glove material type which is suitable for 
Table 6. Substances other than polymers given in higher concentration intervals (only health labeling given)

\begin{tabular}{|c|c|c|c|}
\hline Substance & CAS nr & $\begin{array}{c}\text { Classification (DSD/CLP) } \\
{[15,24]}\end{array}$ & $\begin{array}{c}\text { Highest concentration } \\
\text { interval } \\
(\mathrm{w} / \mathrm{w} \%)\end{array}$ \\
\hline 2-(2-methoxyethoxy)ethanol & $111-77-3$ & Repr. Cat. 3; R63/ Repr. 2 H361 & $30-60$ \\
\hline 1-methoxy-2-propanol & $107-98-2$ & R67/STOT SE 3 H336 & $30-60$ \\
\hline 2-(2-butoxyetoxy)ethanol & $112-34-5$ & Xi; R36/Eye Irrit. 2 H319 & $10-30$ \\
\hline Alcohols C12-14, ethoxylated & $68439-50-9$ & $\begin{array}{l}\text { No DSD class / Acute Tox. } 4 \text { H302, } \\
\text { Eye Dam. } 1 \text { H318, Skin Irrit. } 2 \\
\text { H315 }\end{array}$ & $>25$ \\
\hline Alcohols C9-11, ethoxylated & $68439-46-3$ & $\begin{array}{l}\text { Acute Tox. } 4 \text { H302, Eye Dam. } 1 \\
\text { H318, Skin Irrit. } 2 \text { H315 }\end{array}$ & $15-30$ \\
\hline 2-propanol & $67-63-0$ & $\begin{array}{l}\text { F; R11, Xi; R36, R67/Eye Irrit. } 2 \\
\text { H319, STOT SE } 3 \text { H336 }\end{array}$ & $10-30$ \\
\hline Phosphoric acid & $7664-38-2$ & C; R34/Skin Corr. 1B H314 & $10-30$ \\
\hline Non-ionic surfactant & & $\mathrm{Xi}$; R36/CLP-class unknown & $10-30$ \\
\hline White mineral oil & $8042-47-5$ & $\begin{array}{l}\text { No DSD class / Asp. Tox. 1, H304, } \\
\text { Eye Irrit. } 2 \text { H319 }\end{array}$ & $10-30$ \\
\hline Sodium hypochlorite & $7681-52-9$ & C; R34/Skin Corr. H314 & $30-60$ \\
\hline Sodium carbonate & $497-19-8$ & Xi; R36/Eye Irrit. 2 H319 & $30-80$ \\
\hline Sulphonic acid, sodium salt & $85711-69-9$ & $\begin{array}{l}\text { Ac. Tox. 4, H302, Skin Irrit., H315, } \\
\text { Eye Dam., H318 }\end{array}$ & $10-30$ \\
\hline Ammonia solution & 1336-21-6 & C; R34/Skin Corr. 1B H314 & $10-30$ \\
\hline $\begin{array}{l}\text { EDTA-Na4 (Tetrasodium ethylene diamine } \\
\text { tetraacetate) }\end{array}$ & $64-02-8$ & $\begin{array}{l}\text { Xn, R22, Xi; R41/Acute Tox. 4; } \\
\text { H302, Eye Irrit. 2, H319 }\end{array}$ & $15-25$ \\
\hline
\end{tabular}

DSD - Dangerous Substances Directive; CLP - Classification, Labeling and Packaging regulation; w/w - as in Table 5.

one component may not be suitable for the same component when it is in presence of other components. A common and frequent piece of advice given to the employers found in the SDSs is that choice of gloves should be made after consulting the producer or supplier of the gloves. Breakthrough times are not given. Only in the case of 9 SDSs breakthrough times were stated; 6 of them gave the generic value of over $8 \mathrm{~h}$ and 3 gave $4 \mathrm{~h}$ as the breakthrough time.

As for inhalation, P2 masks and breathers with type-A filter for dust/aerosols and solvents, respectively [22] are the main types of suggested respiratory protective devices.

\section{Physical properties of the products}

Physical properties given are restricted to: the color of the product, physical state, relative density, $\mathrm{pH}$, and in limited cases, boiling points, combustion point and solubility in water. Other physical properties that are relevant and useful in risk assessment, such as vapor pressure, vapor density and volatile organic compounds (VOC)-content where applicable, are not given. Where these items are listed as part of the structure of the SDSs template, it is stated that either these values are unknown or they are not available. Odors of the products are only given as "characteristic" or as "alkali." For products containing perfumes, "Perfume" is given. 


\section{DISCUSSION}

Although cleaning products are assumed to be low-risk chemicals, the risk of use should be properly determined and information for the users should be correct. Conflicting and missing information in the SDSs, as demonstrated in this study, hamper proper risk management in the cleaning sector. The EU-regulation 453/2010 [11] is elaborate, specific and structured on the contents requirements of each of the 16 sections of the SDS, and in the cases where this regulation was followed the SDSs - section on the areas of use of a given product are evidently better defined. Otherwise for the remaining sections, no significant differences from those SDSs yet to be updated in accordance with the new requirements were observed. The quality of the information given in the SDS is inadequate irrespective of the regulation that the supplier of the products followed. Insufficient use description and non-specific safety information do not add any value to the users. Additionally, not indicating areas of use that are "advised against" can result in wrong use, hence increases the risk of exposure to unknown hazards. Elaborate use description is necessary to ensure safe use, and use as intended.

The non-hazardous or irritant classification and the low risk class in the classification scheme are the main presumptions suppliers would use in their consideration of non-hazardous nature of a cleaning product. There is, however, evidence that mixtures composed of components with similar and those with diverse mode of action, exhibit mixture-effect even when the components are present in amounts below their effect point of departure [23], i.e., the lowest experimental dose that showed an effect. Moreover, concentrations used as point of departure in risk assessment should not be equated to zero-effectlevels. Although there is a need to establish components' threshold for contribution to mixture-effect, it cannot be solely based on the concentration of the components, but also on contribution to toxicity [23]. This assessment supports the possibility that cleaning products, though mainly classified as non-hazardous, exhibit hazardous effects more than it is estimated by the Dangerous Substance Directive (DSD) [24] or Classification, Labeling and Packaging (CLP) [15] regulations classification criteria. Hazardous effect, for example to the skin, should be also extended to those products which do not fulfill Dangerous Products Directive (DPD) irritant classification criteria, but may cause harmful effects to the skin through prolonged or repeated use [13].

Control measures congruent with prevention of exposure to organic solvents are mentioned where no solvents are given. Lee et al. [25], when monitoring 2 workplaces, where printing and work with electronics is performed, reported presence of organic solvents that were not mentioned in the SDSs of the products used in those workplaces. Although the products used in those workplaces were different from cleaning products, the findings support the fact that there are substances in the products which are not listed in the SDSs. Welsh et al. [26] demonstrated using various analytical methods and instruments presence of other substances not mentioned in the SDSs of various products in concentrations above their disclosure thresholds. Organic solvents and other unknown substances present in the products compounds, i.e., adding on to hazardous nature of the products. It is then obvious that component information provided is, in most cases, insufficient for suggesting objective and informed risk management measures.

Information on health effects is not elaborate and is, more often than not, incomplete. Therefore, there is lack of thoroughness and clarity of provided toxicological information. Earlier SDS-study concluded that only $37 \%$ of 150 SDSs had accurate information on health effects [20]. Tillberg [27] pointed out that lack of essential information in SDS shows manufacturers' inadequate competence in toxicology. This shows that over time little has changed in SDSs development. Sufficient information is available for some substances in cleaning products, but 
there is bias concerning interpretation of the data [28] and this affects dissemination of correct information. As demonstrated in this study, information in SDSs, normally gathered from different sources gives divergent and sometimes conflicting safety measures.

With respect to PPEs, similar glove material types are suggested for different products despite differences in their composition, area of use and the assigned risk level. Gloves protection factor is not likely to remain the same for various glove types and is influenced to a great extent by period of exposure, work done and product's components concentration [29]. Consequently, where no reliable information is available, a more strict classification such as "toxic in contact with skin (R24)" or "irritates skin (R38)" should be considered on selecting risk management measures [13]. R24 may be extreme, but R38 is more appropriate. One has to be aware of other contributing factors such as the mixture-effect, and should not conclude outright that the product is not hazardous. This precautionary approach is not applied anywhere in the SDSs.

Recommended duration for the use of gloves is a 3rd of the breakthrough time when this is the only known parameter [13]. No other gloves parameters are indicated as seen during assessment of SDSs. Without knowing the breakthrough times, it becomes difficult to determine time duration one can use the gloves without risking possible exposure. Although in many SDSs it is suggested to change gloves frequently, the time between changing the gloves is not specified. On the other hand, suppliers transfer their duty of providing sufficient information on PPEs to the user of the product. Where gloves or other types of PPE are necessary, it is a duty of a supplier to give sufficient information on the most appropriate equipment. Lechtenberg-Auffarth [30] suggested that the gloves product-name suitable for a specific chemical product should be provided in the SDSs.

As for toxicological information, precautions are given for the increased risks with prolonged or repeated use. For many cleaners working full shift, or those working in different places during one day, their work-time is always extended. As such, general expressions on health hazards due to prolonged use again, are of no value to their safety considerations. Generic information is not sufficient enough to allow proper implementation of workplace safety [3]. Preventive measures for prolonged use are mentioned only in few SDSs, but these are likewise generic and only limited to the use of PPEs. It is common that SDSs for different products marketed by the same supplier have identical information in sections 8 and 11 despite varying compositions and their intended use.

Information on physical properties is also scarce. Terms such as "characteristic" or "alkalic" odors give little useful information. Alkali nature of products can be due to various components giving different odors. However, substances with similar structure may give varying odors, e.g., ammonium solution and amines, both with basicity due the nitrogen atom, according to acid-base theory, have distinct odors. Stating that the odor is characteristic, alkalic or perfumed gives no meaningful information to the user. A more elucidative description of the odor would be more useful in enabling users to decide on appropriate risk management measures.

Bernstein [5] pointed that healthcare workers have a duty to learn how to interpret information given in the SDSs and recognize their incompleteness. Tillberg [27] suggested regular examination of SDSs to ensure that information contained is reliable and adequate. These are reasonable and sensible propositions, but for cleaning workers and, to considerable extent, for their employers, the proposals may pose challenges mainly because cleaning workers have no resources and capacities similar to those of healthcare workers. Many, being migrant workers with lower educational background, may lack language and technical competence to decipher the perplexing information and identify what is inadequate therein. Information provided in SDSs 
has to cover the cleaning workers' needs, in terms of adequacy and utility.

It is more and more often the norm that external consultants compile SDSs on behalf of a supplier of the products. This is done using information provided to them and information from other sources they may have access to. Such outsourcing results in the suppliers of the products not having complete command of the content of the SDS. In most cases, a supplier cannot substantiate information given there (inspection reports from the Labour Inspection Authority).

Safety data sheets constitute information source for employers and their employees and other relevant parties, and to many, they are the only source of information on chemicals safety and health related issues. The usefulness and clarity of the SDS as a tool for communication on chemical health hazards consists in the correctness of the information given and how the sections of the SDS complement one another.

\section{CONCLUSION}

Utility of the information given in the SDSs assessed is insufficient and of varying degree of variability, and underscores the continued need to improve the quality of the SDSs for cleaning products and, undoubtedly, also for other chemical products. Critical assessment of the products may lead to more concise and specific health effects and so, appropriate risk management measures.

Based on the ambiguous, and in some cases, contradicting information in different sections of the SDS, users may opt for what might not be the most appropriate risk management measures, but what is construed as such. Consistency and connectivity between various sections of the SDSs is paramount in deriving clear appropriate safe use and handling measures. Inclusion of exposure scenarios in the SDS would result in more specific safety measures. It is conceivable that cleaning workers get exposed to hazardous chemicals as a result of the inadequacy and poor quality of information contained in the SDSs. Underestimation of the hazardous contribution of the components in the products and the poor non-objective mention of the appropriate control and protective measures are the major elements contributing to the problems in the field of risk of exposure of workers to chemicals.

With the wide range of use of the products and the differences in their composition, specified and elaborate health effects and measures more specific to a particular product and area of use should be considered as parameters to be obligatorily included.

\section{ACKNOWLEDGEMENTS}

We would kindly extend our sincere gratitude to Suhayla Salim, Gro Sand, Dr. Risley Ngala and Caroline Schønning-Andreassen for their contribution.

\section{REFERENCES}

1. Direktoratet for Arbeidstilsynet. [Regulation on work performance, use of work equipment and associated technical requirements. Set by Royal Norwegian Ministry of Labour]; 2013 [cited $2013 \mathrm{Jul}$ 20]. Available from: http://lovdata. no/dokument/SF/forskrift/2011-12-06-1357. Norwegian.

2. Nicol AM, Hurrel AC, Wahyuni D, McDowell W, Chu W. Accuracy, comprehensibility, and use of material safety data sheets. A review. Am J Ind Med. 2008;51(11):861-76.

3. Olcert R. Use in well ventilated area. J Am Ind Hyg Assoc. 1999;60(3):337.

4. Keegel T, Saunders H, la Montagne AD, Nixon R. Are material safety data sheets useful in diagnosis and management of occupational contact dermatitis? Contact Dermat. 2007;57(5):331-6.

5. Bernstein J. Material safety data sheets. Are they reliable in identifying human hazards? J Allergy Clinic Immunol. 2002;110(1):35-8. 
6. Carøe TK, Ebbehøj N, Agner T. A survey of exposures related to recognized occupational contact. Contact Dermat. 2014;70(1):56-62.

7. Bauer A. Contact dermatitits in the cleaning industry. Current Opinion. Allergy Clinic Immunol. 2013;13(5):521-4.

8. Folletti I, Zock JP, Moscato G, Siracusa A. Asthma and rhinitis in cleaning workers. A systematic review of epidemiological studies. J Asthma. 2014;51(1):18-28.

9. Siracusa A, de Blay F, Folleti I, Moscato G, Olivieri M, Quirce S, et al. Asthma and exposure to cleaning products. A European Academy of Allergy and Clinical Immunology task force consensus statement. Allergy. 2013;68(12):1532-45.

10. European Parliament and the Council. Directive 1999/45/ EC of 31 May 1999 concerning the approximation of the laws, regulations and administrative provisions of the Member States relating to the classification, packaging and labelling of dangerous preparations (Jul 30, 1999). Available from: http://eur-lex.europa.eu/LexUriServ/LexUriServ.do? uri=OJ:L:1999:200:0001:0068:EN:PDF.

11. European Parliament and the Council. Commission Regulation (EU) No. 453/2010 of 20 May 2010 amending Regulation (EC) No. 1907/2006 of the European Parliament and of the Council on the Registration, Evaluation, Authorization and Restriction of Chemicals (REACH) (May 31, 2010). Available from: http://eur-lex.europa.eu/LexUriServ/LexUriServ.do?uri=OJ:L:2010:133:0001:0043:en:PDF.

12. European Chemical Agency. Guidance on information requirements and chemical safety assessment, chapter R.12: Use descriptor system. Helsinki: EchA; 2010 [cited 2013 Aug 08]. Available from: http://echa.europa.eu/documents/10162/13632/information_requirements_r12_en.pdf.

13. Bundesanstalt für Arbeitsschutz und Arbeitsmedizin. Risks resulting from skin contact - Determination, evaluation, measures; 2006 [cited 2013 Aug 4]. Available from: http:// www.baua.de/nn_54598/en/Topics-from-A-to-Z/HazardousSubstances/TRGS/pdf/TRGS-401.pdf.

14. European Parliament and the Council. Regulation (EC) No. 1907/2006 of 18 December 2006 concerning the Registration,
Evaluation, Authorization and Restriction of Chemicals (REACH), establishing a European Chemicals Agency, amending Directive 1999/45/EC and repealing Council Regulation (EEC) No. 793/93 and Commission Regulation 1488/94 as well as Council Directive 76/769/EEC and Commision Directives 91/155/EEC, 93/105/EC and 2000/21/ EC (Dec 30, 2006). Available from: http://eur-lex.europa.eu/ LexUriServ/LexUriServ.do?uri=OJ:L:2006:396:0001:0849: EN:PDF.

15. European Parliament and Council. Regulation (EC) No. 1272/2008 of 16 December 2008 on classification, labelling and packaging of substances and mixtures, amending and repealing Directives 67/548/EEC and 1999/45/EC, and amending Regulation (EC) No. 1907/2006 (Dec 18, 2008). Available from: http://eur-lex.europa.eu/LexUriServ/LexUriServ.do?uri=OJ:L:2008:339:0078:0081:EN:PDF.

16. Lavoué J, Bégin D, Gérin M. Technical, occupational health and environmental aspects of metal degreasing with aqueous cleaners. Ann Occup Hyg. 2003;47(6):441-59.

17. European Center for Ecotoxicology and Toxicology of Chemicals. Glycol ethers and its relevance to man. 1995; technical report No. 64. Available from: http://www.ecetoc. org/technical-reports.

18. International Program on Chemicals Safety. Quaternary ammonium compounds. Poison Information Monograph (PIM) G022 [Internet]. 1999 [cited 2013 Aug 14]. Available from: http://www.inchem.org/documents/pims/chemi$\mathrm{cal} / \mathrm{pimg} 022 . \mathrm{htm}$.

19. International Program on Chemicals Safety. Linear alkyl benzene sulfonates and related compounds. Environmental Health Criteria 169 [Internet]. 1996 [cited 2013 Aug 14]. Available from: http://www.inchem.org/documents/ehc/ehc/ ehc169.htm.

20. Kolp PW, Williams P, Burtan RC. Assessment of the accuracy of material safety data sheets. J Am Ind Hyg Assoc. 1995;56(2):178-83.

21. Blayney MB. The need for empirically derived permeation data for personal protective equipment: The 
death of Dr. Karen E. Wetterhahn. Appl Occup Envir Hyg. 2001;16(2):233-6.

22. Direktoratet for Arbeidstilsynet. [Information on breathing equipment]. 2002 [cited $2013 \mathrm{Jul}$ 27]. Available from: http:// www.arbeidstilsynet.no/binfil/download2.php?tid $=77748$. Norwegian.

23. Kortenkamp A, Backhaus T, Faust M. State of the art report on mixture toxicity. EU Commission, DG Enterprise study; 2009.

24. European Parliament and Council. Directive 67/548/EEC of 27 June 1967 on the approximation of laws, regulations and administrative provisions relating to the classification, packaging and labelling of dangerous substances (16.8.1967). Available from: http://eur-lex.europa.eu/legal-content/EN/ TXT/PDF/?uri=CELEX:31967L0548\&from=EN.

25. Lee JH, Sohn EK, Ahn JS, Ahn K, Kim KS, Lee TM, et al. Exposure assessment of workers in printed electronics workplace. Inhalation Toxicol. 2013;25(8):426-34, http:// dx.doi.org/10.3109/08958378.2013.800617.

26. Welsh MS, Lamesse M, Karpinski E. The verification of hazardous ingredients disclosures in selected material safety data sheets. Appl Occup Envir Hyg. 2000;15(5):409-20.

27. Tillberg A. A multidisciplinary risk assessment of dental restorative materials. Umeå University Odontological Dissertation. Umeå: Department of Odontology / Dental Technician Programme; 2008 [cited 2013 Aug 7]. Available from: http://umu. diva-portal.org/smash/get/diva2:142221/FULLTEXT01.pdf.

28. Oldershaw P, FairHurst S. Sharing toxicological information on industrial chemicals. Ann Occup Hyg. 2001;45(4):291-4.

29. Cherrie JW, Semple S, Brouwer D. Gloves and dermal exposure to chemicals. Proposals for evaluating workplace effectiveness. Ann Occup Hyg. 2004;48(7):607-15.

30. Lechtenberg-Auffarth E, Rühl R. Safety of gloves for chemicals protection. Ann Occup Hyg. 2007;51(8):739-40.

This work is available in Open Access model and licensed under a Creative Commons Attribution-NonCommercial 3.0 Poland License - http://creativecommons.org/ licenses/by-nc/3.0/pl/deed.en. 